\title{
Arqueologia das práticas alimentares de uma vizinhança no Rio de Janeiro, século XIX:
}

o que a história não conta

\author{
Archaeology of foodways in a neighborhood in 19th century Rio de Janeiro: \\ what history does not tell
}

Tania Andrade Lima ${ }^{1}$

Martha Locks ${ }^{2}$

Com vistas à liberação de uma área para a construção civil no centro do Rio de Janeiro, foi feita uma intervenção arqueológica no seu subsolo, que recuperou os restos materiais de seis unidades habitacionais oitocentistas contíguas. Em meio a uma abundante tralha doméstica de pessoas comuns, fazendo coisas simples no seu dia a dia, foi resgatada uma expressiva quantidade de restos alimentares, em sua esmagadora maioria ossos de mamíferos e aves. Um estudo detalhado das marcas observadas nesses ossos identificou cortes padronizados que remetem às formas de aquisição de carne à época, e as ferramentas e utensílios utilizados para produzi-los; e também ao modo como eles foram processados e consumidos por essa vizinhança, aqui entendida como um conjunto de pessoas que moram em estreita proximidade. Uma análise comparada do que foi encontrado em cada uma das casas permitiu observar os hábitos de consumo desses grupos domésticos e as práticas alimentares que eles adotaram em suas rotinas diárias no Rio de Janeiro do século XIX.

Palavras-chave: arqueologia; restos alimentares; hábitos alimentares; Rio de Janeiro.

Keywords: archaeology; food remains; foodways; Rio de Janeiro.

1 Professora do Departamento de Antropologia do Museu Nacional da Universidade Federal do Rio de Janeiro.

No II Simpósio Internacional de Pesquisa em Alimentação, participou da mesa-redonda "Cultura material ealimentação". 2 Bióloga do Departamento de Antropologia do Museu Nacional da Universidade Federal do Rio de Janeiro. 